\title{
Prevention of Spinal Cord Injuries in Australia
}

John D. Yeo, A.O., M.B., M.S., D.P.R.M., F.R.A.C.S., F.A.C.R.M. ${ }^{1}$ and John Walsh, BSc., A.I.A., F.I.A.A., A.S.A. ${ }^{2}$

${ }^{1}$ Director of the Spinal Unit, ${ }^{2}$ Actuarial Consultant, Spinal Injuries Unit, Royal North Shore Hospital, Pacific Highway, St Leonards, N.S.W. Australia

\begin{abstract}
Summary
An Awareness and Prevention Team of five lecturers has been employed for 5 years funded by the Spinal Research Foundation at the Royal North Shore Hospital of Sydney, New South Wales. An evaluation of the effectiveness of the lecture programme in increasing knowledge and preventing the incidence of spinal cord injury was carried out to demonstrate the justification for continuing the Programme. This evaluation was achieved using a questionnaire designed for sample responses by school students in target age range. The questionnaires were distributed to 27 schools in five categories in order to obtain a spread of responses and a workable control group of schools which had not been visited by the Team. Results of 3823 questionnaires were tabulated and analysed by computer. The schools which had been visited by the Lecture Team showed both higher levels of knowledge on the structure of the spinal cord and effects of injury and also a more balanced attitude and awareness towards people requiring wheelchairs for mobility.
\end{abstract}

\section{Introduction}

An audio-visual programme on Prevention and Awareness was prepared for both Primary and Secondary schools in New South Wales by the staff of the Spinal Injuries Unit of Royal North Shore Hospital of Sydney. The detailed programme resulted from initial visits to schools by specialised medical staff from the hospital with lecturers emphasing special risk areas, such as travelling in motor vehicles without restraint and inadequate protective helmets and clothing while riding motor-cycles. Dangers of diving into shallow water were also emphasised with the need to develop adequate training procedures for those participating in contact sport (Fig. 1). Financial assistance for the project is provided by the Government Insurance Office of New South Wales and amounts to $\$ 220000$ annually. There is also support from the State Department of Sport, Recreation and Tourism. The Team's Programme is co-ordinated by Miss Lyn Ryan, professional School Teacher, who has the responsibility of establishing and maintaining contact with schools, finalising time tables and 
ROYAL NORTH SHORE SPINAL UNIT 1976-1985

YEARLY SUMMARY - BY CAUSE

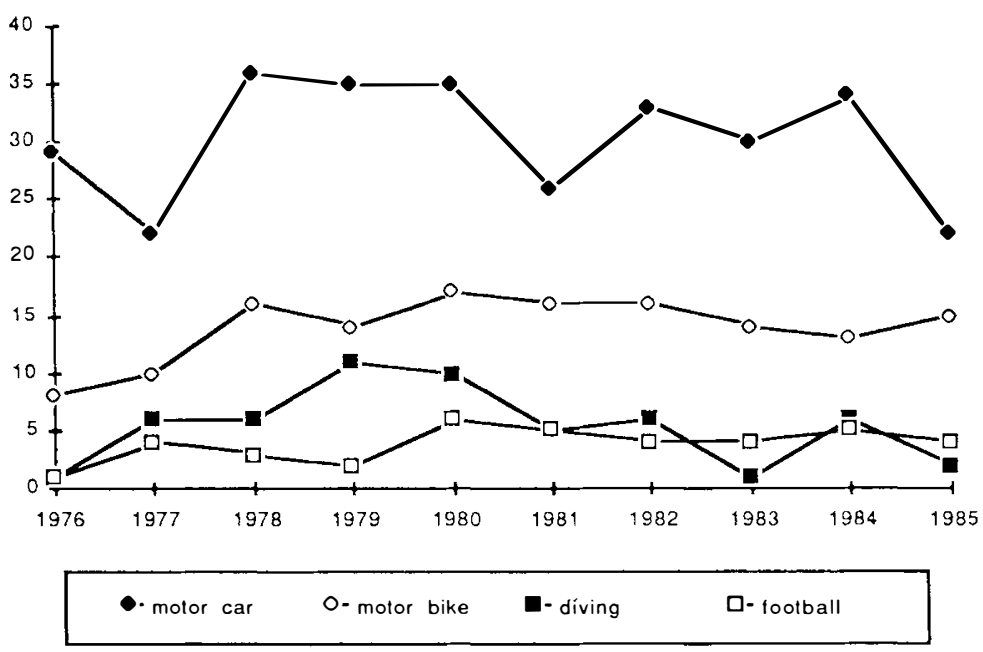

Figure 1 Incidence of spinal cord injury in patients admitted to the Spinal Unit between 1976 and 1985 .

liaising with the media for the production of printed and audio-visual material which is distributed to the contacted schools. The team is assisted by an essential contribution from voluntary workers who assist in the packaging and distribution of pamphlets. At present three quadriplegic and two paraplegic casualties are employed.

The following methods of presentation are used in the Programme.

1. Audio-visual displays; one for Primary schools and the other for older pupils in Secondary schools.

2. Poster and model displays which illustrate the anatomy and function of the spine and spinal cord.

3. A question and answer period where the presenters have an opportunity to speak to students on a less formal level.

4. The distribution of coloured pamphlets which emphasise those points which have been made during the audio-visual presentation.

The aim of the Programme is to make each audience aware of the dangerous pursuits and habits of children and demonstrate ways of minimising the risks (Fig. 2).

The current rate of exposure has increased from 18000 school children in 1982 to 78000 school children during the year 1986 .

\section{Method}

A simple multiple choice questionnaire was developed for distribution to schools. In order to assess the appropriate level of understanding by students a preliminary 'open-ended' questionnaire was distributed to approximately 50 

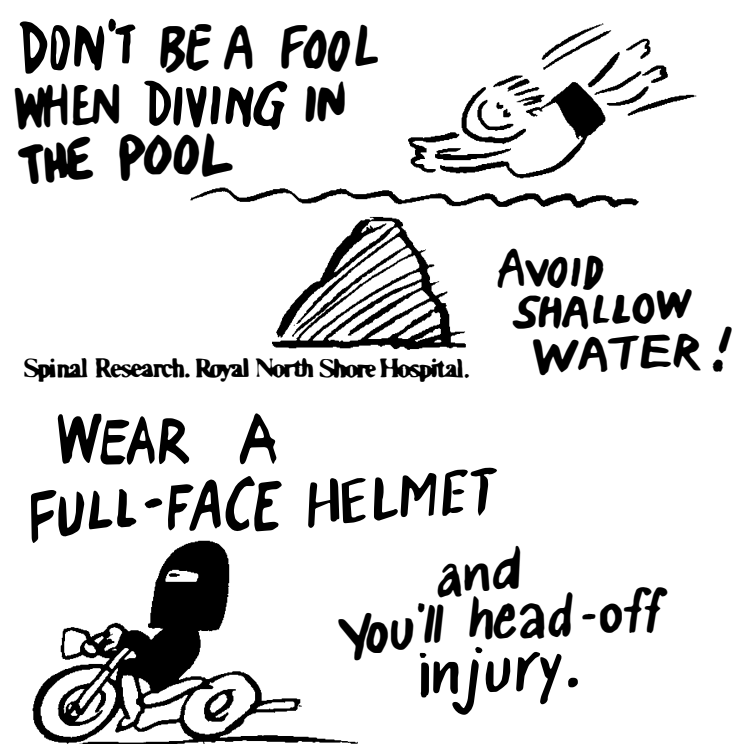

Spinal Research. Roval North Shore Howital.

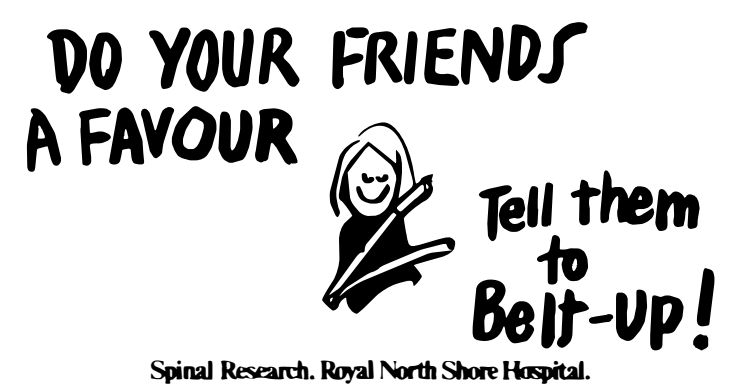

Figure 2 Posters used in school presentations.

children and a cross-section of responses obtained was used in the development of the final questionnaire.

Two multiple-choice questionnaires were then designed; one at Primary school level and one at Secondary school level. Care was taken that the Primary school participants understood the nature of the multiple-choice questions by including a sample multiple-choice question at the start of the form.

The forms were sent to schools and a total of 3823 responses were received from 27 schools. These schools included Primary City and Country schools which had been visited (14) and schools which had not been visited (four). The Secondary schools visited were all within the Greater Metropolitan Areas. Six had been visited by the Lecture Team and three had not been visited. One thousand six hundred and sixteen responses were obtained from the Primary schools and 2207 responses from the Secondary schools. Participants were asked to record their age, year and school and their best answer to 15 multiple-choice questions. The completed forms were then processed and coded through an I.B.M. computer system. Tabulating the questionnaire, three sub-scores were developed for sections on Anatomy, Prevention and Acceptance. 
Answers allowed comparison with:

1. Those schools which had been visited by the Team with those which had not.

2. City schools and Country schools.

3. Primary schools compared with Secondary schools.

The results were:

1. Under every measure tested the schools which had been visited by the Lecturing Team scored significantly better than those which had not been visited.

2. In evaluating the numerical scores the difference was more striking in Primary schools than in Secondary schools and Primary schools generally scored higher (i.e. better response) than Secondary schoolsparticularly in the understanding of Anatomy where questions for Secondary schools were considered more demanding.

3. No significant difference was observed between age groups or year groups.

4. The overall scores indicated that the best 'score' non-visited schools had scores approximating to the scores of the 'worst' visited school.

5. Exposure of children to lecturers with disabilities did not apparently improve the effectiveness of the lecturing when compared with results from those classes lectured by an able-bodied presenter.

\section{Discussion}

This analysis of the Lecturing Programme demonstrated that the Education and Prevention Programmes were successful in increasing knowledge and awareness of the effects of spinal cord injury and improving acceptance by school children of people with spinal cord injury.

The results also emphasise the importance of education in the wearing of seatbelts in cars, protective clothing and helmets while riding a motor-cycle and taking care while swimming to avoid head and neck injury. The aim of the Programme is to reach at least $20 \%$ of the target population in schools in this State. The effectiveness of education is confirmed by the reduction in the incidence of serious spinal cord injury in motor car injury and diving into shallow water. 